\title{
Correlation of panoramic radiograph and CBCT findings in assessment of relationship between impacted mandibular third molars and mandibular canal in Saudi population
}

\author{
Ahmed Nasser ${ }^{*}$, Abdulaziz Altamimi ${ }^{1}$, Ahmed Alomar ${ }^{2}$ and Naif AlOtaibi ${ }^{3}$ \\ ${ }^{1}$ Bachelor of dental surgery, Oral and Maxillofacial department, King Abdulaziz Medical City, Ministry of National Guard Health Affairs, Riyadh, Saudi Arabia \\ ${ }^{2}$ Assistant consultant, Oral and Maxillofacial department, King Khalid university Hospital, King Saud University Medical City, Riyadh, Saudi Arabia \\ ${ }^{3}$ Bachelor of dental surgery, Oral and Maxillofacial department, Prince Sultan Military Medical City, Riyadh, Saudi Arabia
}

\begin{abstract}
Purpose: The aim of this study is to assess the reliability of seven panoramic radiographic markers in predicting the absence of corticalization between the mandibular canal and the third molar which carries the risk of inferior alveolar nerve injury during extraction on cone beam computed tomography images.

Materials and methods: The study samples consisted of 270 impacted third molars from 136 patients who showed a close relationship between the mandibular canal and third molars on panoramic radiographs and were referred for the examination with CBCT to assess the relationship between the tooth and the mandibular canal. Panoramic images were evaluated for the seven radiographic markers. CBCT images were used to assess the continuity of the mandibular canal cortical bone. The association of the panoramic and CBCT findings was examined using a Chi-square test and Fisher's exact test.

Results: Panoramic radiographic markers were statistically associated with CBCT findings $(\mathrm{P}<0.01)$. In cases of darkening roots, interruption of white line as an isolated finding or in association with each other.

Conclusion: Panoramic radiography is an effective and efficient method for the assessment of impacted mandibular third molars. Interruption of white line and darkened roots on panoramic radiographs, as both isolated findings and in association with each other are effective in determining the relationship between the tooth roots and the mandibular canal requiring evaluation with cone beam computed tomography.
\end{abstract}

\section{Introduction}

Extraction of impacted third molars is a procedure in Oral surgery. Whether prophylactic or because of tooth decay, periodontal diseases and recurrent infections [1]. Third molars have a high incidence of impaction, while reports have demonstrated an incidence range of neurosensory impairment after extraction range from $0.5 \%$ to $8 \%$ [2]. Radiographic examination is an essential tool for diagnosis and management as it provides a valuable information about the tooth position, root morphology and its relation to the adjacent and vital structures. Postoperative complications were commonly reversible, although inferior alveolar nerve damage is one of the serious complications as the sensation loss of the lower lip may cause traumatic injuries, fibromas and mucocele formation [3]. There are seven radiographic markers can be seen on panoramic radiographs (darkening of roots; deflection of roots; narrowing of roots; bifid root apex; diversion of canal; narrowing of canal; interruption in the white line of the canal), those markers are reliable to assess the relationship between the third molar and the mandibular canal [4,5]. The clinical implication of cone beam computed tomography have been discussed in several aspects $[5,6]$. However, the patient can be exposed to a higher radiation dose even though conventional radiographic techniques are of high diagnostic value [7]. Therefore, this study was designed to assess the reliability of panoramic seven radiographic markers in detecting radiographic signs as both isolated findings and in association with each other, in predicting the absence of corticalization between the mandibular canal (MC) and impacted mandibular third molars on CBCT images.

\section{Materials and methods}

This was a retrospective study including 270 impacted mandibular third molars, those were collected from 136 patients (86 male and 50 female patients) who showed a close relationship of the MC and impacted mandibular third molars on the panoramic radiograph and were referred to oral and maxillofacial surgery clinics in Dental University Hospital, King Saud University Medical City for assessing the relation between the impacted mandibular third molar and the $\mathrm{MC}$ with $\mathrm{CBCT}$ in preparation for third molar extraction, those were included in the study. Incomplete root formation or individuals with evidence of intra-osseous pathologies on the radiograph like tumors or cysts associated with the third molars were excluded from the study. Two observers evaluated the panoramic and CBCT digital images

Correspondence to: Ahmed Nasser, Bachelor of dental surgery, Oral and Maxillofacial department, King Abdulaziz Medical City, Ministry of National Guard Health Affairs, Riyadh, Saudi Arabia, Tel. +966501314141,

Key words: molar, third, CBCT, panoramic

Received: January 13, 2018; Accepted: February 05, 2018; Published: February 07,2018 
Nasser A (2018) Correlation of panoramic radiograph and CBCT findings in assessment of relationship between impacted mandibular third molars and mandibular canal in Saudi population

independently for the relationship between the impacted mandibular third molars and MC. Seven panoramic radiographic signs were examined: darkening of roots; deflection of roots; narrowing of roots; bifid root apex; Interruption of MC; Diversion of MC; narrowing of MC (Figure 1), the group of markers were further assessed with CBCT to examine the MC cortical bone for its continuity assessing the reliability of panoramic radiograph seven markers in predicting the direct contact of impacted mandibular third molars and the MC. For the evaluation of CBCT digital images, the presence or absence of direct contact between the third molar roots and MC was three-dimensionally evaluated. It was considered that direct contact was present when loss of mandibular canal cortical bone between the two structures was observed on all three sections (Figures 2-4). All of the panoramic radiographs were taken with a Planmeca ProMax 2D S3 and CBCT scans were acquired with a Planmeca ProMax 3D Plus(Planmeca Co., Helsinki, Finland). The CBCT data were reconstructed using Planmeca Romexis software.

\section{Statistical analysis}

Intraobserver and interobserver agreement were evaluated using kappa statistics. We compared panoramic radiographic markers with the relationship between the impacted mandibular third molar and the mandibular canal using CBCT images. The association of panoramic radiograph and $\mathrm{CBCT}$ findings was analyzed using a Chi-square test and Fisher's exact test. All of the analyses were carried out with PASW Statistics 18.0 (SPSS Inc., Chicago, IL, USA).

\section{Results}

A total of 270 impacted mandibular third molars in 136 patients, those from 86 males $(63.7 \%)$ and 50 females (36.3\%) were included in the study. The impacted mandibular third molars were classified according to Pell and Gregory's classification [8], and the distribution of the total sample is listed in (Table 1). The impaction type according to
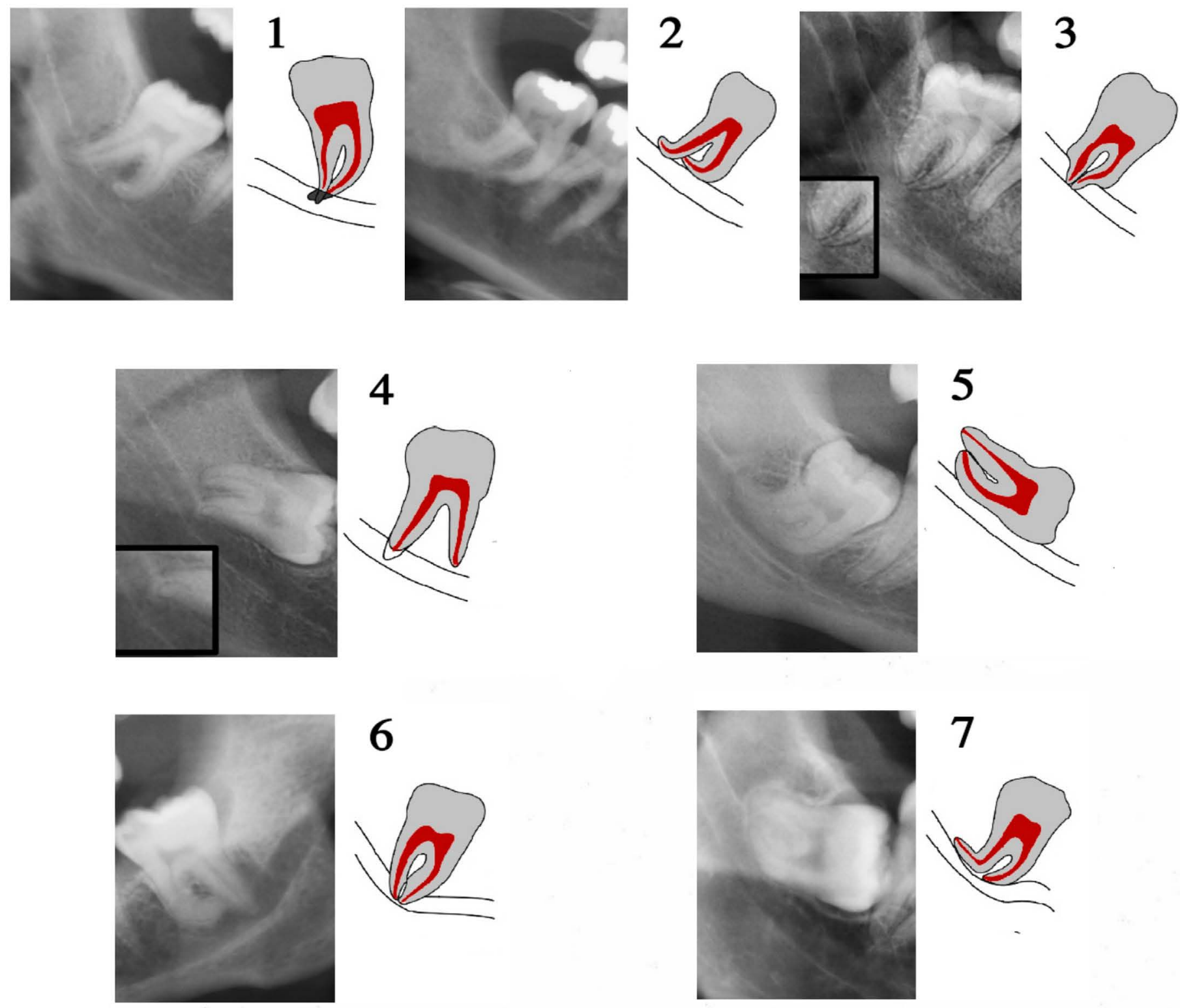

Figure 1. Drawings and cropped panoramic radiographs of the seven panoramic radiographic markers evaluated in the present study. 1, Darkening of root. 2, Root deflection. 3, Narrowing of roots. 4, Bifid apex. 5, Interruption of mandibular canal wall. 6, Diversion of mandibular canal. 7, Narrowing of mandibular canal. 
Nasser A (2018) Correlation of panoramic radiograph and CBCT findings in assessment of relationship between impacted mandibular third molars and mandibular canal in Saudi population

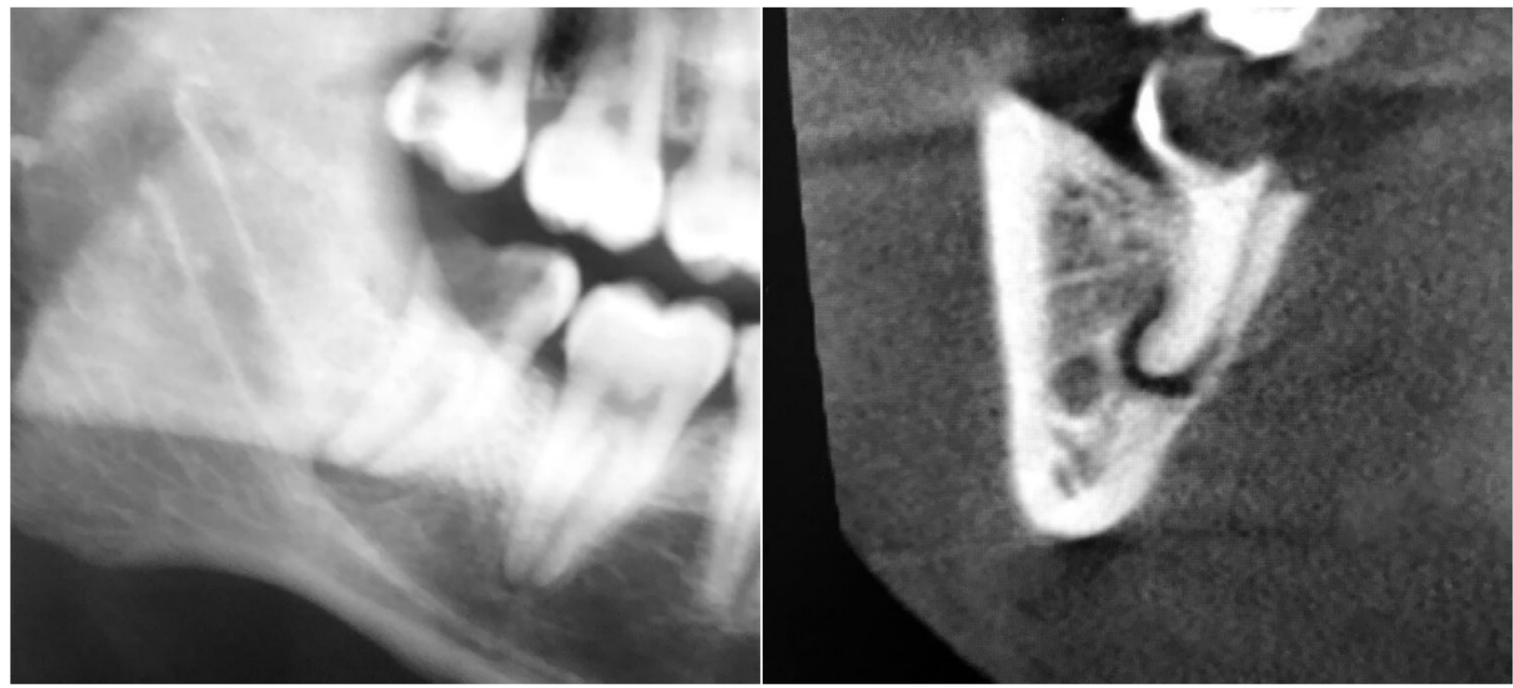

Figure 2. Cropped panoramic radiograph of tooth $\# 48$ with none of the panoramic radiograph signs observed showing no relation with the mandibular canal.
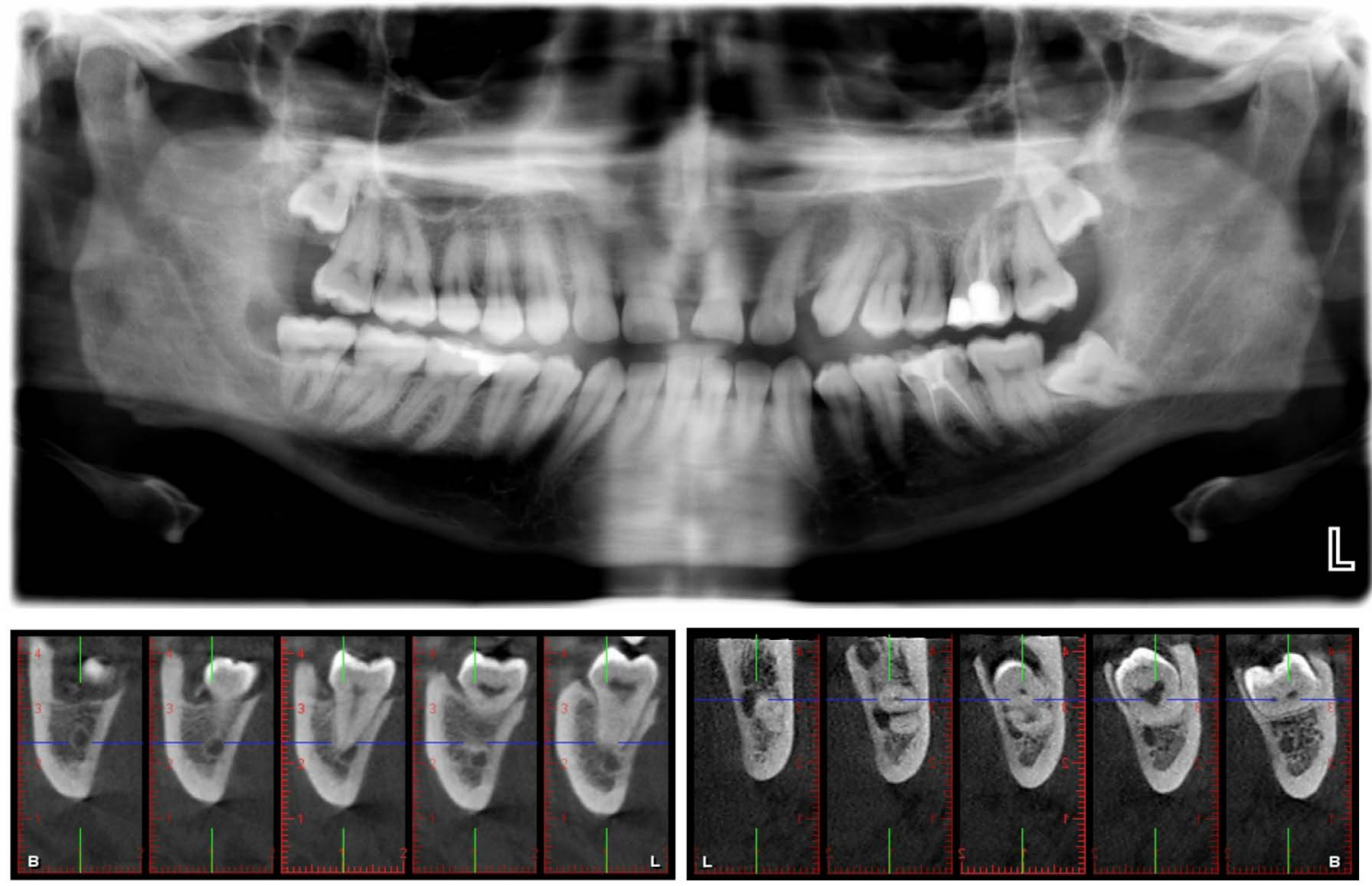

Figure 3. Panoramic radiograph showing a close relationship of teeth $\# 38$, $\# 48$ and the mandibular canal with bilateral discontinuity of the mandibular canal cortical bone observed in the CBCT images resembling the direct contact between the tooth and the inferior alveolar nerve increasing the risk of injury.

Table 1. Impacted mandibular third molar distribution.

\begin{tabular}{|c|c|c|c|c|}
\hline \multirow{2}{*}{ Impaction type } & \multicolumn{2}{|c|}{ Tooth side } & \multirow{2}{*}{$\mathbf{n}$} & \multirow{2}{*}{$\%$} \\
\hline & Right & Left & & \\
\hline Vertical & 46 & 52 & 98 & $36.30 \%$ \\
\hline Mesioangular & 42 & 44 & 86 & $31.85 \%$ \\
\hline Horizontal & 37 & 32 & 69 & $25.56 \%$ \\
\hline Distoangular & 8 & 6 & 14 & $5.18 \%$ \\
\hline Buccal deflection & 0 & 1 & 1 & $0.37 \%$ \\
\hline Lingual deflection & 1 & 1 & 2 & $0.74 \%$ \\
\hline Total & 134 & 136 & 270 & $100 \%$ \\
\hline
\end{tabular}



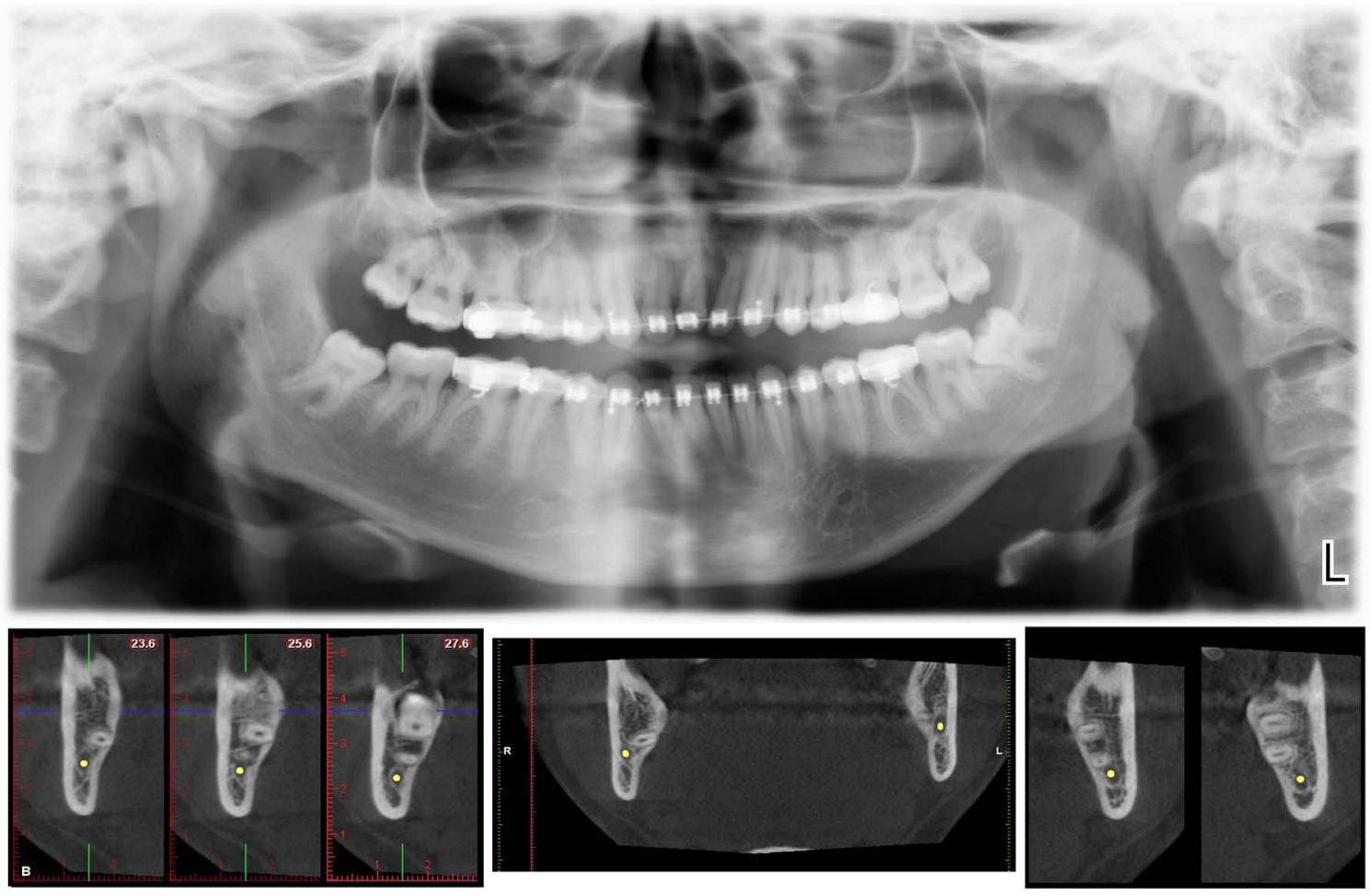

Figure 4. Panoramic radiograph showing a close relationship of teeth \#38, \#48 and the mandibular canal while no discontinuity was observed of the mandibular canal cortical bone in the CBCT images decreasing the risk of nerve injury.

Pell and Gregory's classification [8] was compared with the presence or absence of true relationship with the mandibular canal. Horizontal and mesioangular impactions showed a statistically significant association with the absence of corticalization showing a true relationship listed in (Table 2). The correlation between panoramic radiograph and CBCT findings based on the relationship between mandibular impacted third molars and the mandibular canal is listed in (Table 3). Interruption of white line and darkening of roots, as an isolated finding $(\mathrm{p}=0.0005$ and $\mathrm{p}=0.0001)$ or in association with each other $(\mathrm{p}=0.002)$, demonstrated a statistically significant association with the absence of corticalization between the mandibular impacted third molar and the mandibular canal in CBCT images indicating a true relationship. The mandibular canal is outlined by cortical bone that isolates its contents from the adjacent structures, "True relationship" is when there is discontinuity of the cortical bone between the tooth root and the mandibular canal.

\section{Discussion}

Radiographic diagnosis prior extracting impacted mandibular third molar is critical to evaluate the depth of impaction and root morphology and its relation to mandibular canal to predict the risk of postsurgical extraction. Feifel $\mathrm{H}$, et al. [9] found that teeth in a true relationship to the Inferior alveolar canal, the incidence of nerve injury increases as high as $35.6 \%$. Periapical radiograph obtained via parallel technique, panoramic radiograph can be requested to assess impacted mandibular third molars to make the diagnosis and to establish the proper treatment plan, although the panoramic radiograph has an image distortion of $20 \%$ compared with the patient's true anatomy [10]. The accuracy of classifying tooth impactions was no higher than $50 \%$ [11]. However, cone beam computed tomography can be taken enabling the maxillofacial surgeon to assess the case in different planes with an increase in image definitions in cases with high risk of nerve injury. Tantanapornkul, et al. [12] reported that Cone-beam CT was significantly superior to panoramic images in predicting neurovascular bundle exposure during extraction of impacted mandibular third molars, the sensitivity and specificity were $93 \%$ and $77 \%$ for conebeam CT, and $70 \%$ and $63 \%$ for panoramic images. Ferretti F, et al. [13] conducted a study regarding the usefulness of Magnetic resonance imaging in the evaluation of the relationships between the impacted mandibular third molars and mandibular canal and found that MRI can be used to provide similar information instead of CT or CBCT in young patients to prevent radiation exposure. The risk of true relation between the impacted mandibular third molar and the mandibular canal increases as the amount of covering increased [14]. Nakamori, et al. [15] among other studies [16,17] are suggesting the evaluation using cone beam computed tomography when specific signs are observed in the panoramic radiograph. In our present study, most panoramic radiographic signs were interruption of white line (35.6\%) and darkening of roots $(27.2 \%)$, these results conform with those in previous studies [16-18]. In the present study, Interruption of white line and darkening of roots associated with discontinuity of the mandibular canal and absence of corticalization between the impacted mandibular third molar and the mandibular canal in cone beam computed tomography images were statistically significant, as both isolated findings and in association with each other. The close relationship of impacted mandibular third molar roots and the mandibular canal can increase the risk of inferior alveolar nerve exposure during the extraction or as a postsurgical complication with subsequent nerve injury. Ghaeminia, et al. [19] Jhamb A, et al. [16] reported that interruption of white line, darkening of roots and diversion of the mandibular canal were associated with inferior alveolar nerve exposure significantly. Sewrin and Andreasen [20] and Rood [4] reported that there were lower lip paresthesia in $17 \%$ of cases of increased radiolucency of third molar roots, and $14 \%$ of cases of 
Nasser A (2018) Correlation of panoramic radiograph and CBCT findings in assessment of relationship between impacted mandibular third molars and mandibular canal in Saudi population

Table 2. Type of impaction and its association with the mandibular canal.

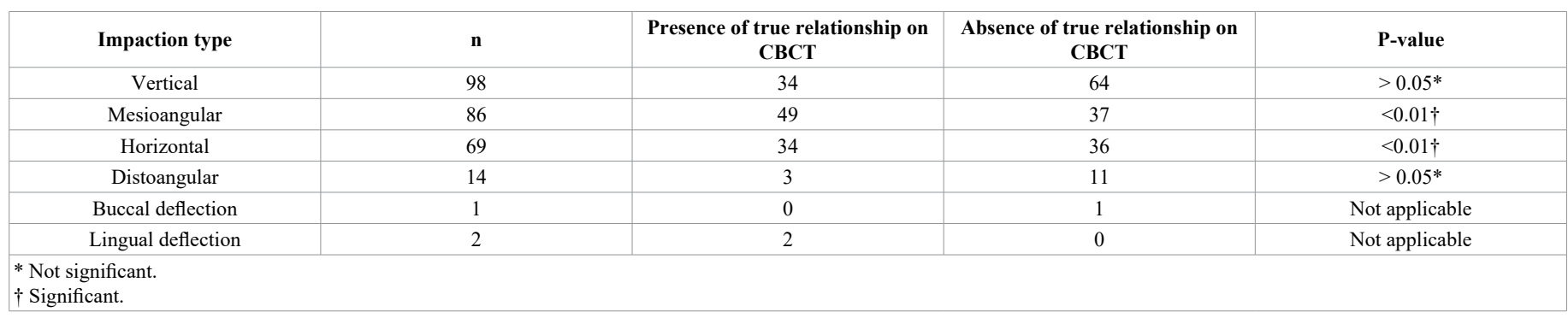

Table 3. The correlation between panoramic and CBCT findings.

\begin{tabular}{|c|c|c|c|c|}
\hline Radiographic finding & Cases in panoramic radiograph & $\begin{array}{c}\text { Presence of corticalization in } \\
\text { CBCT images }\end{array}$ & $\begin{array}{l}\text { Absence of corticalization } \\
\text { in CBCT images }\end{array}$ & P-value \\
\hline Darkening of roots & 117 & 39 & 78 & $<0.01 \dagger$ \\
\hline Root deflection & 60 & 28 & 32 & $>0.05^{*}$ \\
\hline Narrowing of roots & 34 & 20 & 14 & $>0.05^{*}$ \\
\hline Narrowing of mandibular canal & 36 & 15 & 21 & $>0.05^{*}$ \\
\hline Interruption of white line & 156 & 58 & 98 & $<0.01 \dagger$ \\
\hline $\begin{array}{l}\text { Darkening of roots }+ \\
\text { Interruption of white line }\end{array}$ & 93 & 29 & 64 & $<0.01 \dagger$ \\
\hline \multicolumn{5}{|l|}{$\begin{array}{l}\text { * NOT SIGNIFICANT. } \\
+ \text { SIGNIFICANT. }\end{array}$} \\
\hline
\end{tabular}

interruption of white line which was the absence of corticalization of the superior corticated margin of the mandibular canal. However, the knowledge of this relationship allows the surgeon to manage the case.

\section{Ethical approval}

Ethical approval for this study was provided by the Ethical Committee of the Institutional Review Board, King Saud University College Of Medicine, King Saud University Medical City on 6 November 2017.

\section{References}

1. Bataineh AB (2001) Sensory nerve impairment following mandibular third molar surgery. J Oral Maxillofac Surg 59: 1012-1017. [Crossref]

2. Nakagawa Y, Ishii H, Nomura Y, Watanabe NY, Hoshiba D, et al. (2007) Third molar position: Reliability of panoramic radiography. J Oral Maxillofac Surg 65: 1303-1308. [Crossref]

3. Szalma JCB, Lempel E, Jeges S, Szabó G, Olasz L (2010) The prognostic value of panoramic radiography of inferior alveolar nerve damage after mandibular third molar removal: retrospective study of 400 cases. Oral Surg Oral Med Oral Pathol Oral Radiol Endod 109: 294-302. [Crossref]

4. Rood J, Shehab BN (1990) The radiological prediction of inferior alveolar nerve injury during third molar surgery. Br J Oral Maxillofac Surg 28: 20-25. [Crossref]

5. Blaeser BF, August MA, Donoff R, Kaban LB, Dodson TB (2003) Panoramic radiographic risk factors for inferior alveolar nerve injury after third molar extraction. J Oral Maxillofac Surg 61: 417-421. [Crossref]

6. Gomes ACCAA, Vasconcelos BCDE, Silva EDDO, Caldas ADF, Neto ICP (2008) Sensitivity and specificity of pantomography to predict inferior alveolar nerve damage during extraction of impacted lower third molars. J Oral Maxillofac Surg 66: 256-259. [Crossref]

7. Li G (2013) Patient radiation dose and protection from cone-beam computed tomography. Imaging Sci Dent 43: 63-69. [Crossref]

8. Pell GJ, Gregory GT (1933) Impacted mandibular third molars: classification and modified technique for removal. Dental Digest 39: 330-336.

9. Feifel H, Riediger D, Gustorf-Aeckerle R (1994) High resolution computed tomography of the inferior alveolar and lingual nerves. Neuroradiology 36: 236-238. [Crossref]

10. Smith AC, Barry SE, Chiong AY, Hadzakis D, Kha S-L, et al. (1997) Inferior alveolar nerve demage following removal of mandibular third molar teeth. A prospective study using panoramic radiography. Aust Dent J 42: 149-152. [Crossref]
11. Chandler LP, Laskin DM (1988) Accuracy of radiographs in classification of impacted third molar teeth. J Oral Maxillofac Surg 46: 656-660. [Crossref]

12. Tantanapornkul W, Okouchi K, Fujiwara Y, Yamashiro M, Maruoka Y, et al. (2007) A comparative study of cone-beam computed tomography and conventional panoramic radiography in assessing the topographic relationship between the mandibular canal and impacted third molars. Oral Surg Oral Med Oral Pathol Oral Radiol Endod 103 253-259. [Crossref]

13. Ferretti F, Malventi M, Malasoma R (2009) Dental magnetic resonance imaging: study of impacted mandibular third molars. Dentomaxillofac Radiol 38: 387-392. [Crossref]

14. Monaco G, Montevecchi M, Bonetti GA, Gatto MRA, Checchi L (2004) Reliability of panoramic radiography in evaluating the topographic relationship between the mandibular canal and impacted third molars. J Am Dent Assoc 135: 312-318. [Crossref]

15. Nakamori K, Fujiwara K, Miyazaki A, Tomihara K, Tsuji M, et al. (2008) Clinical assessment of the relationship between the third molar and the inferior alveolar canal using panoramic images and computed tomography. J Oral Maxillofac Surg 66: 23082313. [Crossref]

16. Jhamb A, Dolas RS, Pandilwar PK, Mohanty S (2009) Comparative efficacy of spiral computed tomography and orthopantomography in preoperative detection of relation of inferior alveolar neurovascular bundle to the impacted mandibular third molar. J Oral Maxillofac Surg 67: 58-66. [Crossref]

17. Khan I, Halli R, Gadre P, Gadre KS (2011) Correlation of panoramic radiographs and spiral CT scan in the preoperative assessment of intimacy of the inferior alveolar canal to impacted mandibular third molars. J Craniofac Surg 22: 566-570. [Crossref]

18. Maaytah ME, Jerjes W, Swinson B, Upile T, Thompson G, et al. (2007) Inferior alveolar nerve injury and surgical difficulty prediction in third molar surgery: The role of dental panoramic tomography. British Journal of Oral and Maxillofacial Surgery 45.

19. Ghaeminia H, Meijer G, Soehardi A, Borstlap W, Mulder J, Bergé S (2009) Position of the impacted third molar in relation to the mandibular canal. Diagnostic accuracy of cone beam computed tomography compared with panoramic radiography. Int J Oral Maxillofac Surg 38: 964-971. [Crossref]

20. Andreasen JO, Petersen JK, Laskin DM (1997) Textbook and color atlas of tooth impactions: diagnosis, treatment and prevention. Estados Unidos: Mosby.

Copyright: (C2018 Nasser A. This is an open-access article distributed under the terms of the Creative Commons Attribution License, which permits unrestricted use, distribution, and reproduction in any medium, provided the original author and source are credited. 